\title{
Safety and Efficacy of Prefilled Liquid Etanercept- Biosimilar Yisaipu for Active Ankylosing Spondylitis: A Multi-Center Phase III Trial
}

\author{
Dongbao Zhao · Dongyi He $\cdot$ Liqi Bi $\cdot$ Huaxiang Wu Yi Liu • \\ Zhenbiao Wu • Yang Li · Guochun Wang · Xingfu Li • \\ Chunde Bao · Lindi Jiang · Zhiyi Zhang • Weiguo Xiao • \\ Gang Tong · Dong Wang · Feng Huang
}

Received: November 18, 2020 / Accepted: January 6, 2021 / Published online: February 9, 2021

(C) The Author(s) 2021

\section{ABSTRACT}

Introduction: The aim of this work is to examine the efficacy and safety of prefilled liquid etanercept-biosimilar Yisaipu versus lyophilized Yisaipu in active ankylosing spondylitis (AS) patients.

Supplementary Information The online version contains supplementary material available at https:// doi.org/10.1007/s40744-021-00276-1.

\section{Zhao}

Department of Rheumatology and Immunology, Changhai Hospital, Naval Medical University, Shanghai, China

D. He

Department of Rheumatology, Guanghua Hospital, Shanghai University of Traditional Chinese

Medicine, Shanghai, China

L. Bi

Department of Rheumatology and Immunology,

China-Japan Union Hospital of Jilin University,

Changchun, Jilin Province, China

H. $\mathrm{Wu}$

Department of Rheumatology, The Second Affiliated Hospital of Zhejiang University School of Medicine, Hangzhou, Zhejiang Province, China

Y. Liu

Department of Rheumatology, West China Hospital, Sichuan University, Chengdu, Sichuan Province, China
Methods: This double-blind, phase III trial with non-inferiority design randomized adult patients with active AS in a 3:1:1 ratio to receive twice-weekly 25-mg prefilled liquid Yisaipu for a total of 48 injections (group I, $n=330$ ), onceweekly 50-mg prefilled liquid Yisaipu for 24 injections (group II, $n=110$ ), or twice-weekly 25-mg lyophilized Yisaipu for 48 injections (group III, $n=110$ ). Both physicians and patients who received 25-mg twice-weekly lyophilized or liquid Yisaipu were blinded to treatment assignment while patients who received 50-mg once-weekly liquid Yisaipu

\section{Z. $\mathrm{Wu}$}

Department of Rheumatology, The First Affiliated Hospital of Air Force Medical University of PLA, Xi'an, Shaanxi Province, China

\section{Y. Li}

Department of Rheumatology and Immunology, The Second Affiliated Hospital of Harbin Medical University, Harbin, Heilongjiang Province, China

\section{G. Wang}

Department of Rheumatology, China-Japan

Friendship Hospital, Beijing, China

\section{Li}

Department of Rheumatology, Qilu Hospital of Shandong University, Jinan, Shandong Province, China

\section{Bao}

Department of Rheumatology and Immunology, Renji Hospital Affiliated to Shanghai Jiaotong University School of Medicine, Shanghai, China 
received treatment in an open-label design. In addition, 90 patients in the PK/PD study were randomized in a 1:1:1 ratio to each group. The primary outcome was the proportion of patients who achieved ASAS20 at week 24.

Results: A total of 640 subjects were enrolled. The proportion of patients who attained ASAS20 at week 24 was $85.56 \%$ in group I, $85.71 \%$ in group II, and $83.45 \%$ in group III (group I vs. III, $P=0.545$; group II vs. III, $P=0.605)$. The difference between group I and III was $2.10 \%(95 \% \mathrm{CI}-5.06 \%, 9.27 \%)$ and $2.26 \% \quad(95 \%$ CI $-6.21 \%, 10.73 \%)$ between group II and III, meeting the non-inferiority threshold $(\Delta=-15 \%)(P<0.001)$. Except for a statistical difference between group I $(75.83 \%)$ and group III at week $8(64.75 \%, P=0.011)$, there was no statistical difference in the ASAS20 attainment rate among the three groups at other time points. The incidence of serious adverse events was comparable among the three groups (group I, $2.50 \%$, II, $2.86 \%$ and III, $1.43 \%$; $P>0.05)$. No deaths were reported.

Conclusions: Once-weekly 50-mg or twiceweekly 25-mg prefilled liquid Yisaipu is safe and non-inferior to twice-weekly 25-mg lyophilized Yisaipu.

Trial Registration: CTR20130124 and NCT04345458.

L. Jiang

Department of Rheumatology and Immunology,

Zhongshan Hospital, Fudan University, Shanghai,

China

Z. Zhang

Department of Rheumatology, The First Affiliated

Hospital of Harbin Medical University, Harbin,

Heilongjiang Province, China

W. Xiao

Department of Rheumatology, The First Hospital of

China Medical University, Shenyang, Liaoning

Province, China

G. Tong · D. Wang

Medical Department, R\&D, Sunshine Guojian

Pharmaceutical (Shanghai) Co., Ltd, Shanghai,

China

F. Huang $(\bowtie)$

Department of Rheumatology and Immunology,

Chinese PLA General Hospital, Beijing, China

e-mail: fhuang@301hospital.com.cn
Keywords: Biological therapies; Clinical trials and methods; Immunosuppressants; Pharmacology; Spondylitis

\section{Key Summary Points}

\section{Why carry out this study?}

Ankylosing spondylitis has an estimated prevalence of $0.9 \%$ worldwide and $0.29 \%$ in China.

Etanercept targets tumor necrosis factor $\alpha$ (TNF- $\alpha$ ), which is elevated in the serum, synovium, and sacroiliac joints of ankylosing spondylitis patients.

This non-inferiority trial compares the efficacy and safety of prefilled liquid Yisaipu, an etanercept biosimilar, versus lyophilized Yisaipu in active ankylosing spondylitis patients.

\section{What was learned from the study?}

Once-weekly 50-mg or twice-weekly 25-mg prefilled liquid Yisaipu is safe and non-inferior to twice-weekly $25-\mathrm{mg}$ lyophilized Yisaipu.

Prefilled liquid Yisaipu provides rapid, significant, and sustained improvement in Chinese active ankylosing spondylitis patients.

\section{DIGITAL FEATURES}

This article is published with digital features, including a summary slide, to facilitate understanding of the article. To view digital features for this article go to https://doi.org/10.6084/ m9.figshare.13469847.

\section{INTRODUCTION}

Ankylosing spondylitis is a chronic inflammatory disease characterized by axial skeletal ankylosis and enthesitis [1]. The estimated 
prevalence is $0.9 \%$ worldwide [2], and $0.29 \%$ in China [3], with a 3:1 male-to-female ratio. Major symptoms include back pain, alternating buttock pain and morning stiffness [4]. Ankylosing spondylitis may be associated with progressive irreversible structural damage due to syndesmophyte formation and ankylosis of the vertebral column.

Immune-mediated mechanisms involving human leucocyte antigen (HLA)-B27, inflammatory cellular infiltrates, cytokines such as IL10 and TGF- $\beta$ and genetic and environmental factors may play key roles in ankylosing spondylitis pathogenesis. Tumor necrosis factor $\alpha(\mathrm{TNF}-\alpha)$ has been found to be elevated in the serum, synovium, and sacroiliac joints in ankylosing spondylitis patients $[5,6]$. The American College of Rheumatology, and the Spondyloarthritis Research and Treatment Network treatment guidelines recommend antiTNF therapy for patients with active ankylosing spondylitis [7]. Etanercept is a fusion protein consisting of a Fc portion of immunoglobulin G linked to human TNF- $\alpha$ receptor with potent anti-inflammatory activities [8]. Etanercept could rapidly improve ankylosing spondylitis in a sustained manner [9-11].

Lyophilized etanercept is available as solution injection, prefilled syringe, and prefilled pens. Lyophilized Yisaipu, an etanercept biosimilar, was approved in 2005 by China Food and Drug Administration (CFDA) for rheumatoid arthritis and subsequently for ankylosing spondylitis. Prefilled syringe with liquid Yisaipu was later approved in China. In this multi-center phase III non-inferiority trial, we compared the efficacy and safety of prefilled liquid Yisaipu versus lyophilized Yisaipu in active ankylosing spondylitis patients.

\section{METHODS}

\section{Study Design and Patients}

This is a multi-center double-blind, phase III parallel-group trial with non-inferiority design. The trial was conducted between March 6, 2014 and July 13, 2015. Adult patients with active ankylosing spondylitis (18-65 years of age) were eligible. Ankylosing spondylitis was diagnosed using the 1966 New York clinical criteria. Active ankylosing spondylitis was defined by the Bath Ankylosing Spondylitis Disease Activity Index (BASDAI) $\geq 4$ on the visual analogue scale (VAS) and a VAS score $\geq 4$ for nocturnal back pain $[12,13]$. Main inclusion criteria were (1) inadequate control despite treatment with NSAIDs and oral corticosteroids for $\geq 4$ weeks prior to randomization; (2) treatment with NSAIDs at stable doses for $\geq 2$ weeks before randomization; (3) discontinuation of oral glucocorticoids for $\geq 4$ weeks and local glucocorticoids for $\geq 12$ weeks prior to randomization, or prednisone $\leq 10 \mathrm{mg} /$ day or equivalent for $\geq 4$ weeks prior to randomization; (4) discontinuation of synthetic disease-modifying anti-rheumatic drugs (DMARDs) for $\geq 4$ weeks before randomization, or DMARDs treatment at stable doses for $\geq 4$ weeks before randomization. Main exclusion criteria were (1) clinical or radiographic evidence of complete spinal ankylosis (2) known allergy to human immunoglobulin or Yisaipu or its excipient; (3) inadequate control despite receipt of TNF antagonist therapy for $\geq 3$ months; (4) current or a history of recurrent infections, or a serious liver, renal, hematologic, or neurologic disorder; (5) receipt of organ transplant within 6 months; (6) presence of other autoimmune disease; (7) receipt of herbal medicine, physiotherapy, inactivated or attenuated viral/bacterial vaccines, or intravenous immunoglobulins within 4 weeks; (7) receipt of other biological products or participation in other study drugs within 3 months; (8) pregnant or lactating women.

This study was funded by Sunshine Guojian Pharmaceutical Co., Shanghai, China, and approved by the State Food and Drug Administration of China (Permit No. 2013L01518). The study protocol adhered to the SPIRIT statement [14] and was approved by the ethics committee of all participating institutions (Appendix I). All study subjects provided written informed consent prior to enrollment. The trial is registered with Chinadrugtrials.org.cn (CTR20130124) and ClinicalTrials.gov (NCT04345458). The trial was conducted in accordance with the 
Declaration of Helsinki and the reporting of the study adhered to the CONSORT statement [15].

\section{Randomization}

The study used block randomization. Patients were randomized in a 3:1:1 ratio in a block of five to receive twice-weekly $25-\mathrm{mg}$ prefilled liquid Yisaipu for a total of 48 injections (group I, $n=330$ ) or once-weekly 50-mg prefilled liquid Yisaipu for a total of 24 injections (group II, $n=110$ ), or twice-weekly 25-mg lyophilized Yisaipu for a total of 48 injections (group III, $n=110$ ). In addition, 90 patients in the PK/PD study were randomized in a $1: 1: 1$ ratio in a block of three to each group. Both physicians and patients who received 25-mg twice-weekly lyophilized or liquid Yisaipu were blinded to treatment assignment while patients who received 5-mg once-weekly liquid Yisaipu received treatment in an open-label design.

\section{Patient Assessment}

Assessment was made using the criteria by the Axial SpondyloArthritis international Society (ASAS) Ankylosing Spondylitis Working Group. ASAS20 was defined as an improvement of $\geq 20 \%$ in at least three of the following four domains: (1) global VAS, (2) nocturnal back pain and total back pain VAS, (3) Bath AS Functional Index (BASFI) VAS, and (4) inflammation (intensity and duration of morning stiffness components from the BASDAI); an absolute improvement of at least one unit relative to baseline VAS score; no worsening in the remaining domain [16]. ASAS40 was defined as improvement of $\geq 40 \%$ in at least three of the four domains and an absolute improvement of $\geq 2$ points versus baseline VAS scores and no worsening versus the baseline in the fourth domain. Partial remission was defined as VAS scores $\leq 2$ in each of the four domains. ASAS 5/ 6 was defined as an improvement of $\geq 20 \%$ in at least five of the following six domains: (1) Creactive protein (CRP), and (2) spinal mobility (scoliosis) in addition to the four above-mentioned domains. The Ankylosing Spondylitis Disease Activity Score (ASDAS)-CRP was calculated by using VAS scores from three BASDAI components, patient global assessment VAS, and CRP (mg/l) with the following equation:

$$
\begin{aligned}
& \text { ASDAS }- \text { CRP }=0.121 * \text { Back Pain } \\
& \quad+0.06 \times \text { Duration of Moring stiffness } \\
& \quad+0.11 \times \text { Patient Global } \\
& +0.073 \times \text { Peripheral Pain } / \text { Swelling } \\
& \quad+0.579 \times \operatorname{Ln}(C R P+1)
\end{aligned}
$$

A change $\geq 1.1$ units was considered clinically important improvement and a change $\geq 2.0$ units was deemed clinically major improvement. BASDAI 50 was defined as $\geq 50 \%$ improvement versus the baseline BASDAI. Poor efficacy was defined as active ankylosing spondylitis or failure to attain ASAS20 despite strict compliance with $\geq 12$ weeks of treatment as specified in the study protocol. Limitation of movement was assessed using Bath Ankylosing Spondylitis Metrology Index (BASMI), with higher BASMI scores indicating more severe limitation. The Maastricht Ankylosing Spondylitis Enthesitis Score (MASES) was used to assess enthesitis [17].

\section{Outcome Measures}

Efficacy was evaluated at weeks 2, 4, 8, 12, 16, 20 , and 24. Primary efficacy outcome was the proportion of patients achieving ASAS20 at week 24. Secondary efficacy outcomes included the proportion of patients achieving ASAS40, ASAS partial remission, ASAS 5/6, the ASDAS clinically important and major improvement and inactive disease, BASDAI 50, improvement in BASDAI, BASFI, and BASMI scores, MASES, nocturnal back pain and total back pain VAS, patient global assessment and physician global assessment, number of swollen joints and number of tender joints, and improvement in ESR and CRP at weeks 12 and 24 .

\section{Safety Assessment}

Routine laboratory tests (blood routine, urine routine, liver function, and kidney function) were conducted at weeks $2,4,8,12,16,20$, and 
24. Chest radiograph and 12-lead ECG were recorded upon enrollment and at week 24 . Adverse events (AEs), adverse reactions and changes in laboratory values were recorded at weeks $2,4,8,12,16,20$, and 24 and coded to a preferred term using the Medical Dictionary for Regulatory Activities (MedDRA). AEs were reviewed and determined from the medical history and laboratory findings or from telephone follow-up and graded on a scale derived from the Common Toxicity Criteria of the National Cancer Institute [18]. Safety events included AEs and severe adverse events (SAEs) from the first dose of the study drug. SAEs were defined according to ICH-GCP guidelines and included any untoward medical occurrence that resulted in death, was life-threatening, required hospitalization or prolongation of hospitalization, or caused significant or persistent disability or incapacity, or birth defects [19].

\section{Statistical Analysis}

Assuming one-sided $\alpha=2.5 \%, \beta=20 \%$ and a dropout rate of at least 10\%, 330 in group I, and 110 each in group II and III are needed.

Statistical analyses were performed using SAS version 9.1.3 (SAS Institute Inc., Cary, NC, USA). Analysis of efficacy followed the intention-to-treat (ITT) principle. For missing data, we used the last observation carried forward method for analysis. All patients with a baseline assessment and at least one post-baseline assessment were included in the full analysis set (FAS). The per protocol set (PPS) included patients who had completed the study follow up and efficacy assessment and without major protocol violations. Patients who received at least one treatment and were assessed for safety were included in the safety set. Categorical variables were described in frequency and percentage and compared with Chi-square test, Fisher's exact test, or Cochran-Mantel-Haenszel $(\mathrm{CMH})$ test. Continuous variables were described in mean and standard deviation (SD), or median and quartiles (Q1, Q3) and compared with Student's $t$ test or Wilcoxon signed sum test. The primary efficacy outcome was analyzed using $\mathrm{CMH}$ test that was controlled for baseline variables and center effects to establish 95\% confidence interval $(95 \% \mathrm{CI})$. The non-inferiority threshold $(\Delta)$ was set at $-15 \%$ and noninferiority was established if the lower limit of 95\% CI was greater than the non-inferiority threshold. $P \leq 0.025$ was considered statistically significant. In addition, the binary logistics regression analysis was also used to compare the difference of ASAS20 attainment at week 24 between groups controlled for center effects.

\section{RESULTS}

\section{Demographic and Baseline Characteristics}

A total of 792 patients were screened for eligibility (Fig. 1); 152 were excluded due to the following reasons: not meeting diagnostic criteria for active ankylosing spondylitis $(n=14)$, tuberculosis $(n=44)$, hepatitis B $(n=43)$, laboratory abnormalities $(n=25)$, lack of informed consent $(n=23)$, and others $(n=3)$. Finally, 640 patients (including 90 patients from the PK/ PD study) were randomized to receive twiceweekly 25-mg prefilled liquid Yisaipu $(n=360$; group I), once-weekly 50-mg prefilled liquid Yisaipu ( $n=140$; group II), or twice-weekly 25-mg lyophilized Yisaipu ( $n=140$; group III). The FAS included 360 patients in group I, 140 patients in group II and 139 patients in group III. Thirty-seven patients dropped out of the study and were excluded from the PPS. The PPS included 336 patients in group I, 136 patients in group II, and 131 in group III. Majority of the patients $(84.8 \%)$ were men and $85.0 \%$ of the patients were HLA-B27-positive (Table 1). All patients received medication for ankylosing spondylitis and $52.58 \%$ of the patients received combination therapy. The three groups were comparable in demographic and baseline variables.

\section{Primary Efficacy Outcome}

At week 24, the proportion of patients who attained ASAS20 was $85.56 \%$ in group I, $85.71 \%$ in group II, and $83.45 \%$ in group III (group I vs. III, $P=0.545 ;$ group II vs. III, $P=0.605$ ) 


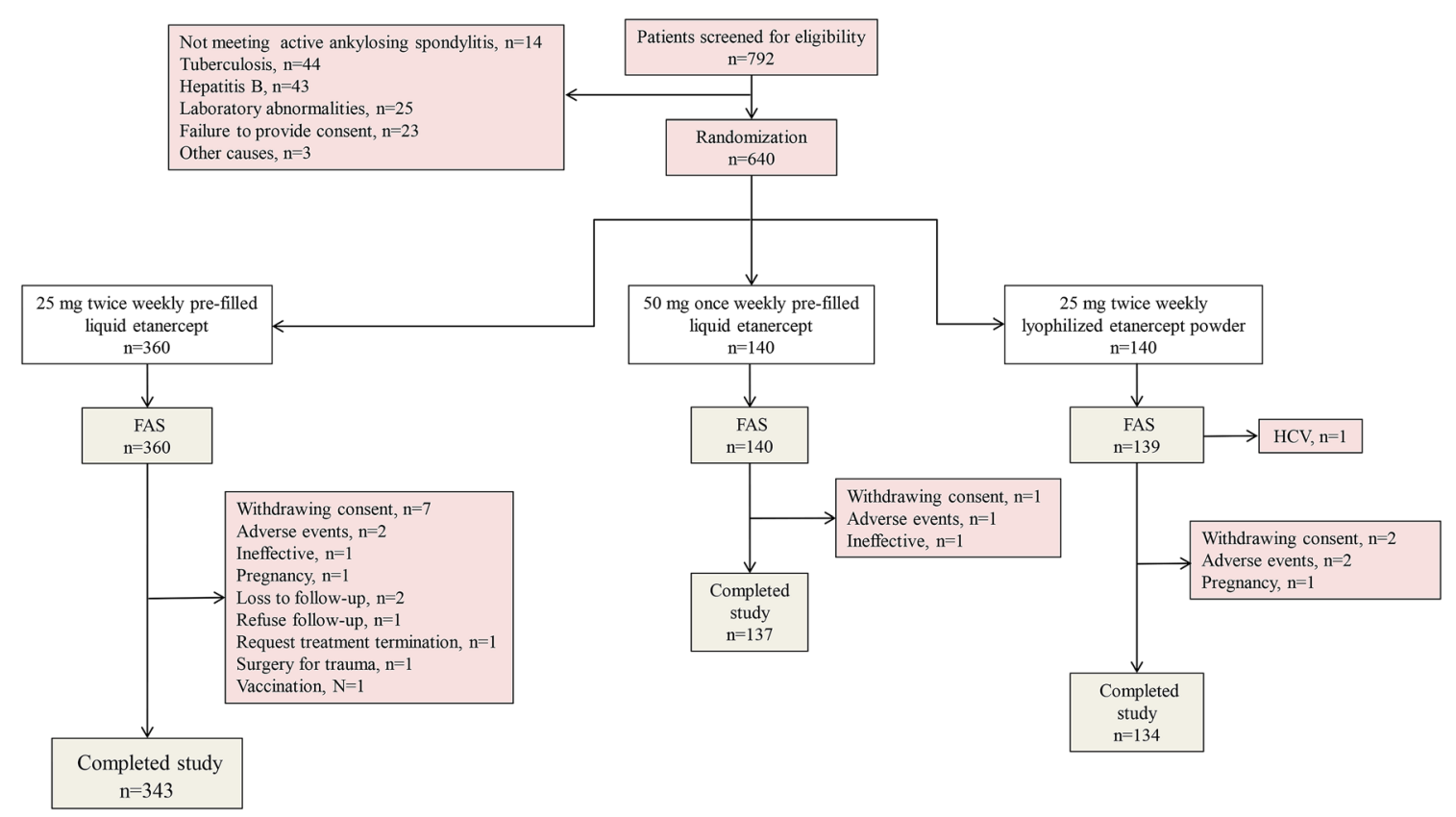

Fig. 1 The study flowchart

(Table 2). The difference in the rate of achieving ASAS20 between groups I and III was $2.10 \%$ (95\% CI $-5.06 \%, 9.27 \%)$, meeting the non-inferiority threshold $(P<0.001)$. The difference in the ASAS20 attainment rate between groups II and III was $2.26 \%$ (95\% CI $-6.21 \%, 10.73 \%)$ and the lower limit of $95 \%$ CI was greater than the non-inferiority threshold $(\Delta=-15 \%)$. Logistic regression analysis also suggested no difference between groups I and III, and between groups II and III (Supplementary Table 1, 2). There was no significant center effect.

\section{Secondary Efficacy Outcomes}

The ASAS40 attainment rate was $62.22 \%$ in group I, $60.00 \%$ in group II, and $60.43 \%$ in group III at week $12(P>0.05)$ and increased to $72.50 \%$ in group I, $72.86 \%$ in group II, and $71.94 \%$ in group III at week $24(P>0.05)$. The difference in the ASAS40 attainment rate between groups I and III was 1.79\% (95\% CI $7.76 \%, 11.34 \%)$ at week 12 and $0.56 \%$ $(95 \% \mathrm{CI}-8.22 \%, 9.34 \%)$ at week 24 . The difference in the ASAS40 attainment rate between groups II and III was - 0.43\% (95\% CI - 11.92\%,
$11.05 \%)$ at week 12 and $0.91 \%$ (95\% CI - 9.58\%, $11.41 \%)$ at week 24 . With an exception at week 8 (56.94\% in group I vs. $46.76 \%$ in group III, $P=0.028)$, there was no difference between groups I and III (Fig. 2a). ASAS40 attainment rate at week 24 did not differ between groups II and III.

The ASAS partial remission rate was 32.22 , 29.29 , and $30.94 \%$ at week 12 in groups I, II, and III, respectively, and increased to 50.83, 45.00 , and $49.64 \%$ at week 24 , with no difference among the three groups (Fig. 2b). The ASAS $5 / 6$ rate was $65.00 \%$ in group I, $66.43 \%$ in group II, and $57.55 \%$ in group III at week 12 and increased to $71.67 \%$ in group I, $77.86 \%$ in group II, and $67.63 \%$ in group III at week 24 , with no difference among the three groups (Supplementary Fig. 1a). The ASAS clinically important improvement and major improvement also did not differ among the three groups (Figs. 1b, 2c).

The BASDAI 50 improvement rate was $57.31 \%$ in group I, $57.55 \%$ in group II, and $55.80 \%$ in group III at week $12(P>0.05)$ and increased to $76.01 \%$ in group I, $74.64 \%$ in group II, and $69.12 \%$ in group III at week 24 $(P>0.05)$. With the exception of higher rate in group I vs. group III (70.32 vs. 61.48\%, 


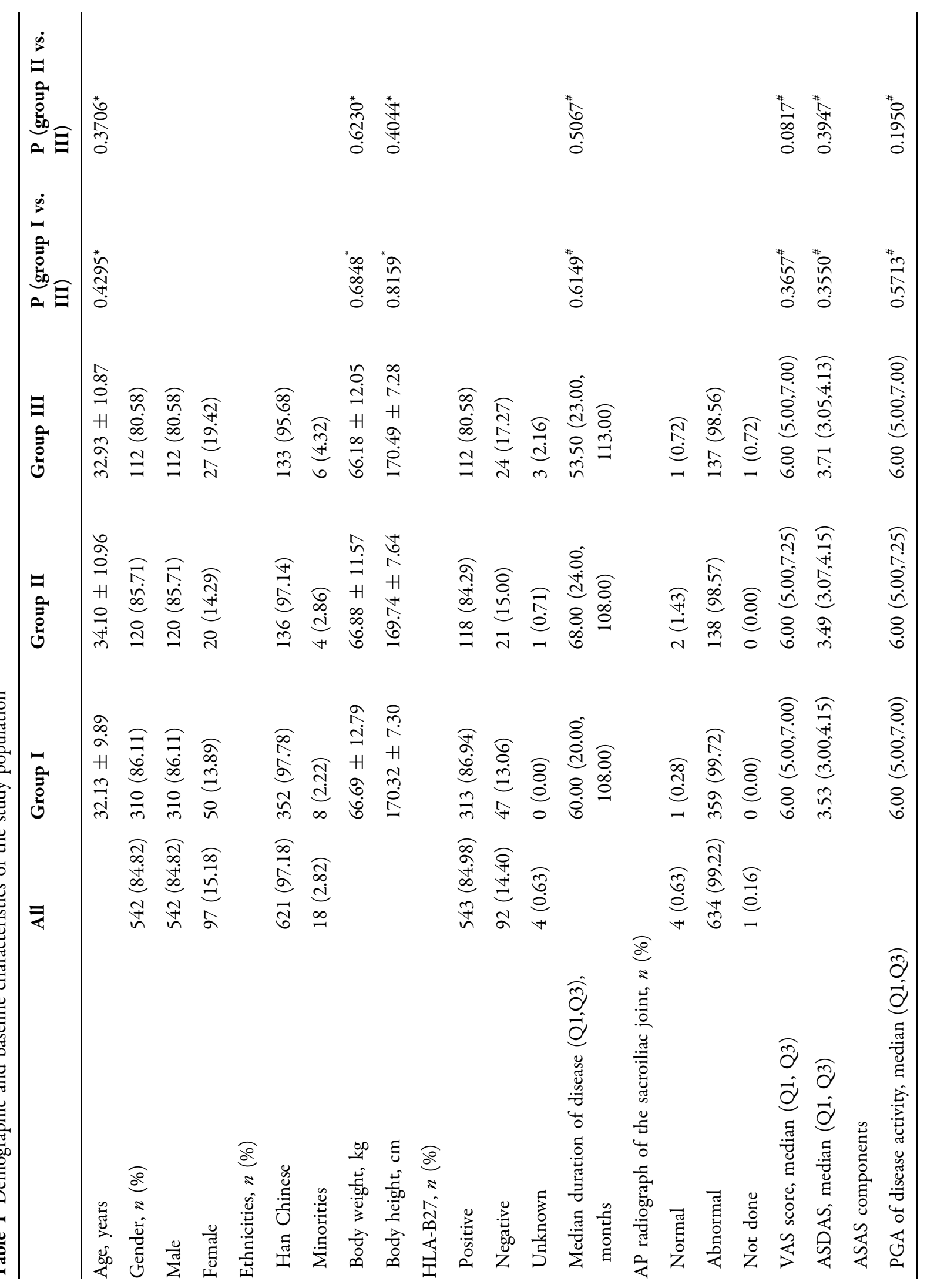




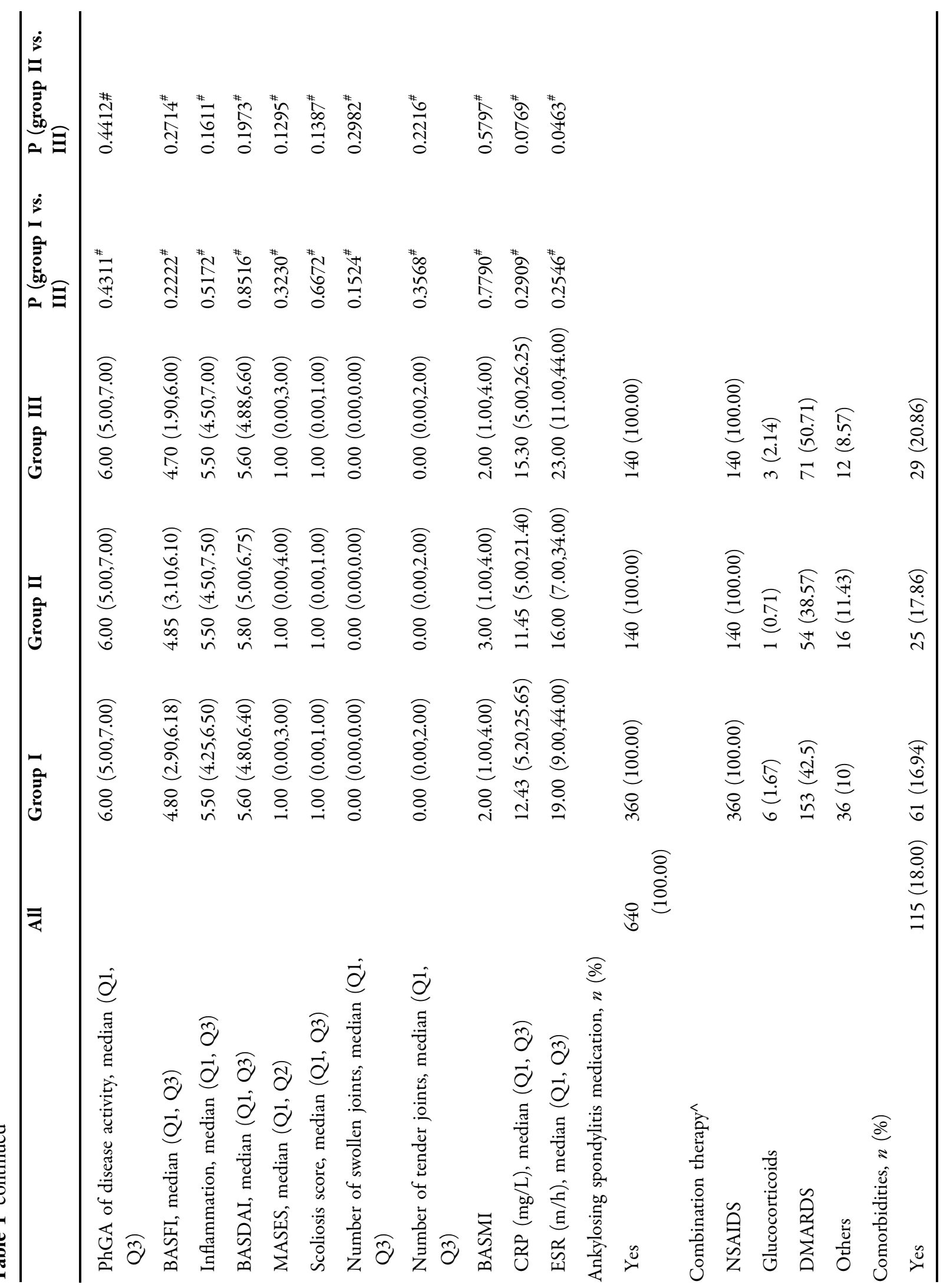




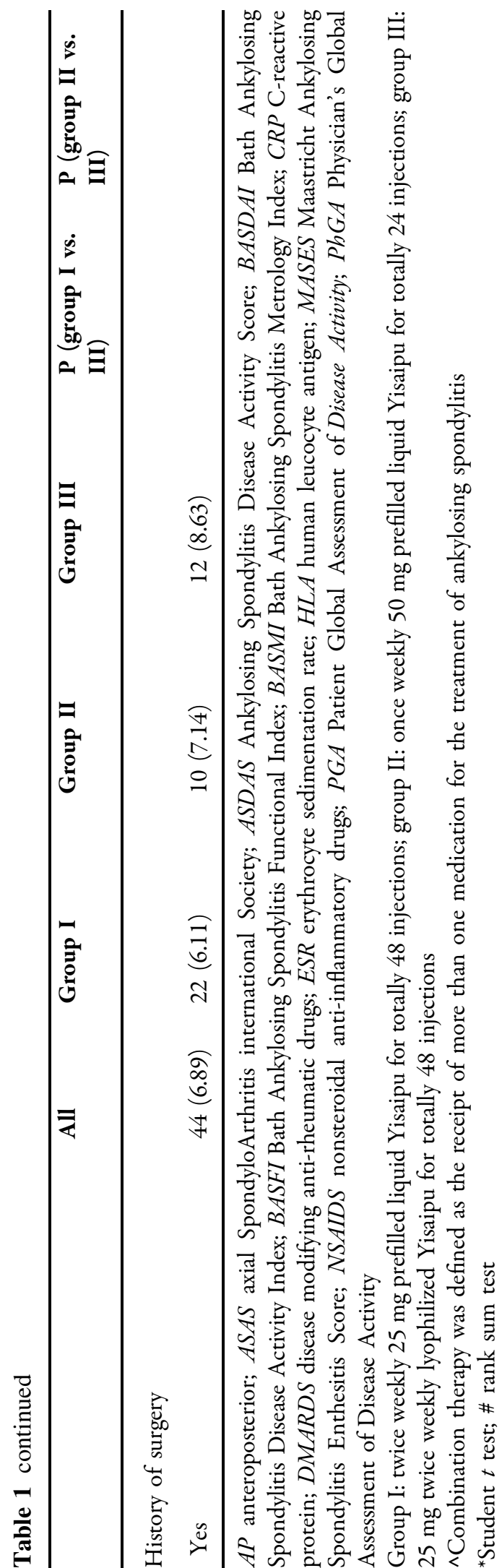

$P=0.029)$ at week 20 , there was no difference among the three groups (Fig. 2d). The median improvement in physical function (BASFI) at week 12 from baseline was significant in group I (2.10 (Q1, Q3 0.95, 3.40)), II (2.00 (Q1, Q3 0.95, 3.65)), and III (1.40 (Q1, Q3 0.40, 3.30)) $(P<0.001)$; the difference was significant between groups I and III $(P=0.018)$, but not between groups II and III $(P>0.05)$. The median improvement in BASFI at week 24 from baseline was significant in group I (2.79 (Q1, Q3 $1.50,4.10))$, II $(2.63(\mathrm{Q} 1, \mathrm{Q} 31.50,4.00))$ and III (2.20 (Q1, Q3 0.50, 4.00)) $(P<0.001)$; the difference was significant between the groups I and III $(P=0.023)$, but not between groups II and III $(P>0.05) \quad$ (Fig. $2 \mathrm{e})$. The median improvement in BASMI scores at week 12 from baseline was significant in group I (1.00 (Q1, Q3 $0.00,2.00))$, II (1.00 (Q1, Q3 0.00, 2.00)), and III $(1.00(\mathrm{Q} 1, \mathrm{Q} 30.00,2.00))(P<0.001)$, with no significant difference among the three groups $(P>0.05)$ (Fig. 2f). The median improvement in BASMI scores at week 24 from baseline was significant in group I (1.00 (Q1, Q3 0.00, 2.00), II (1.00 (Q1, Q3 0.00, 2.00)), and III (1.00 (Q1, Q3 $0.00,2.00))(P<0.001)$ with no significant difference among the three groups $(P>0.05)$. There was a significant improvement in the patients' global assessments of disease activity at week 12 versus baseline in group I (median 3.00 (Q1, Q3 2.00, 5.00), II (median 3.00 (Q1, Q3 2.00, 5.00)), and III (median3.00 (Q1, Q3 $2.00,4.00))(P<0.001)$. A significant improvement was also observed in the patients' global assessments of disease activity at week 24 versus baseline for groups I, II, and III $(P<0.001)$. There was a steady improvement in the patients' as well as physicians' global assessments of disease activity throughout the study period (Supplementary Fig. 1c, d). Other secondary efficacy outcomes at week 24 are provided in Supplementary Table 3.

\section{Safety}

The safety data set included 640 patients. No death occurred during the study period and no cancer cases were reported. The three groups did not differ in AEs, SAEs, adverse reactions and 
Table 2 The ASAS 20 attainment rate of liquid Yisaipu versus lyophilized Yisaipu for active ankylosing spondylitis-FAS

\begin{tabular}{llllllll}
\hline $\begin{array}{l}\text { Post } \\
\text { treatment }\end{array}$ & $\begin{array}{l}\text { Group } \\
\text { I }\end{array}$ & $\begin{array}{l}\text { Group } \\
\text { II }\end{array}$ & $\begin{array}{l}\text { Group } \\
\text { III }\end{array}$ & $\begin{array}{l}\boldsymbol{P}^{*} \\
\text { (group } \\
\text { I vs. } \\
\text { III) }\end{array}$ & $\begin{array}{l}\boldsymbol{P}^{*} \\
\text { (group } \\
\text { II vs. } \\
\text { III) }\end{array}$ & $\begin{array}{l}\text { Difference in ASAS 20 } \\
\text { attainment rate [\% (95\% } \\
\text { CI) (group I vs. III) }\end{array}$ & $\begin{array}{l}\text { Difference in ASAS 20 } \\
\text { attainment rate [\% (95\% } \\
\text { CI)] (group II vs. III) }\end{array}$ \\
\hline Week 2 & 50.28 & 50.00 & 51.08 & 0.952 & 0.853 & $-0.80(-10.59,8.98)$ & $-1.08(-12.81,10.65)$ \\
Week 4 & 66.94 & 65.71 & 60.43 & 0.186 & 0.328 & $6.51(-2.96,15.98)$ & $5.28(-6.03,16.59)$ \\
Week 8 & 75.83 & 75.00 & 64.75 & $0.011^{*}$ & 0.056 & $11.09(1.99,20.18)$ & $10.25(-0.45,20.95)$ \\
Week 12 & 78.89 & 77.14 & 72.66 & 0.135 & 0.353 & $6.23(-2.30,14.75)$ & $4.48(-5.68,14.64)$ \\
Week 16 & 82.50 & 78.57 & 78.42 & 0.294 & 0.981 & $4.08(-3.80,11.97)$ & $0.15(-9.49,9.80)$ \\
Week 20 & 83.89 & 80.71 & 80.58 & 0.359 & 0.981 & $3.31(-4.28,10.91)$ & $0.14(-9.13,9.41)$ \\
Week 24 & 85.56 & 85.71 & 83.45 & 0.545 & 0.605 & $2.10(-5.06,9.27)$ & $2.26(-6.21,10.73)$ \\
\hline
\end{tabular}

Group I: twice-weekly $25 \mathrm{mg}$ prefilled liquid Yisaipu for totally 48 injections; group II: once-weekly $50 \mathrm{mg}$ prefilled liquid Yisaipu for totally 24 injections; group III: $25 \mathrm{mg}$ twice-weekly lyophilized Yisaipu for totally 48 injections

${ }^{*} \mathrm{CMH}$ test
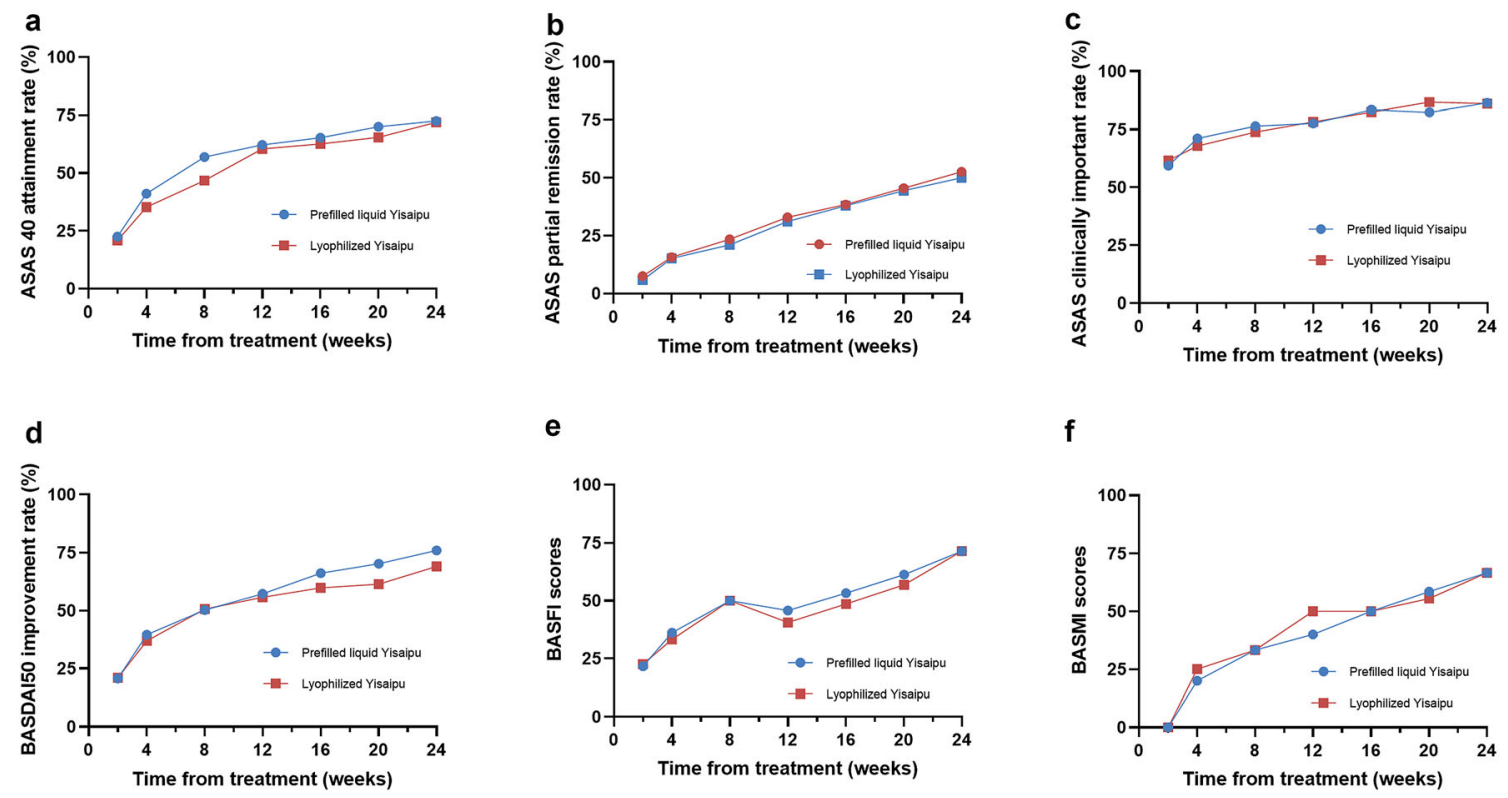

Fig. 2 a ASAS40 attainment rate at weeks 2-24. b ASAS partial remission rate at weeks 2-24. c ASAS clinically important improvement rate at weeks 2-24. d BASDAI 50 improvement rate. e Improvement in BASFI scores at weeks 2-24 versus baseline. f Improvement in BASMI scores at weeks 2-24 versus baseline. ASAS Axial
SpondyloArthritis international Society; BASDAI Bath Ankylosing Spondylitis Disease Activity Index; $B A S F I$ Bath AS Functional Index; BASMI Bath Ankylosing Spondylitis Metrology Index 
Table 3 Incidence of safety events in the study population

\begin{tabular}{|c|c|c|c|c|c|c|c|c|c|}
\hline & \multicolumn{3}{|l|}{ Group I } & \multicolumn{3}{|l|}{ Group II } & \multicolumn{3}{|l|}{ Group III } \\
\hline & $\begin{array}{l}\text { No. of } \\
\text { incidences }\end{array}$ & $\begin{array}{l}\text { No. } \\
\text { of } \\
\text { cases }\end{array}$ & $\begin{array}{l}\text { Incidence } \\
\text { rate }(\%)\end{array}$ & $\begin{array}{l}\text { No. of } \\
\text { incidences }\end{array}$ & $\begin{array}{l}\text { No. } \\
\text { of } \\
\text { cases }\end{array}$ & $\begin{array}{l}\text { Incidence } \\
\text { rate (\%) }\end{array}$ & $\begin{array}{l}\text { No. of } \\
\text { incidences }\end{array}$ & $\begin{array}{l}\text { No. } \\
\text { of } \\
\text { cases }\end{array}$ & $\begin{array}{l}\text { Incidence } \\
\text { rate (\%) }\end{array}$ \\
\hline AEs & 427 & 208 & 57.78 & 185 & 77 & 55.00 & 151 & 74 & 52.86 \\
\hline Adverse reactions & 334 & 182 & 50.56 & 129 & 71 & 50.71 & 109 & 60 & 42.86 \\
\hline SAEs & 9 & 9 & 2.50 & 7 & 4 & 2.86 & 2 & 2 & 1.43 \\
\hline $\begin{array}{l}\text { Serious adverse } \\
\text { reactions }\end{array}$ & 5 & 5 & 1.39 & 5 & 2 & 1.43 & 0 & 0 & 0.00 \\
\hline Important AEs & 270 & 155 & 43.06 & 112 & 52 & 37.14 & 102 & 54 & 38.57 \\
\hline $\begin{array}{l}\text { AEs causing } \\
\text { termination }\end{array}$ & 4 & 4 & 1.11 & 4 & 2 & 1.43 & 3 & 3 & 2.14 \\
\hline $\begin{array}{l}\text { Adverse reactions } \\
\text { causing } \\
\text { termination }\end{array}$ & 2 & 2 & 0.56 & 4 & 2 & 1.43 & 2 & 2 & 1.43 \\
\hline
\end{tabular}

$A E$ adverse event; $S A E$ serious adverse event

Table 4 Adverse events (AEs) with an incidence of at least $5 \%$

\begin{tabular}{llll}
\hline AEs & $\begin{array}{l}\text { Group } \\
\text { I }\end{array}$ & $\begin{array}{l}\text { Group } \\
\text { II }\end{array}$ & $\begin{array}{l}\text { Group } \\
\text { III }\end{array}$ \\
\hline $\begin{array}{l}\text { Upper respiratory tract } \\
\text { infections }\end{array}$ & 21.11 & 19.29 & 14.29 \\
$\begin{array}{l}\text { Elevated hepatic enzymes } \\
\text { Elevated alanine }\end{array}$ & 15.56 & 14.29 & 12.86 \\
$\quad$ aminotransferase & 6.11 & 7.86 & 3.57 \\
Injection site reactions & 6.11 & 5.71 & 2.86 \\
Decreased leucocyte counts & 5.00 & 5.00 & 5.00 \\
\hline
\end{tabular}

serious adverse reactions, and AEs and adverse reactions that caused termination of treatment (Table 3). AEs with an incidence rate of $\geq 5 \%$ are shown in Table 4 . The rate of upper respiratory tract infections was $21.11 \%$ in group I, $19.29 \%$ in group II, and $14.29 \%$ in group III. Elevations in hepatic enzymes occurred in $15.56 \%$ in group I, $14.29 \%$ in group II, and $12.86 \%$ in group III. Decreased leucocyte count was seen in 5\% of the patients in each group. Elevated alanine aminotransferase was seen in $6.11,7.86$, and $3.57 \%$ in groups I, II and III, respectively. Injection site reaction occurred in $6.11 \%$ in group I, $5.71 \%$ in group II, and $2.86 \%$ in group III. SAEs are described in Supplementary Table 4 . Three cases of infections (one each for tuberculosis, infectious pneumonia, and anal abscess) were reported in group I; no infection was seen in groups II and III. Hemangioma was detected in one case in group II and myelodysplastic syndrome was observed in one case in group II. In addition, uveitis was reported in one $(0.71 \%)$ patient in group III and none in the other two groups $(P=0.280)$. No cases of inflammatory bowel disease occurred.

\section{DISCUSSION}

Current treatment guidelines recommend antiTNF therapy for patients with active ankylosing spondylitis despite therapy with nonsteroidal anti-inflammatory drugs (NSAIDs) [7]. Etanercept has been shown to be safe and effective in Chinese ankylosing spondylitis patients [11]. 
Results from the current trial demonstrated that prefilled liquid etanercept-Yisaipu has a rapid onset of action with half of the patients achieving ASAS20 at week 2 and approximately $86 \%$ of the patients achieving ASAS20 at week 24 and twice-weekly 25-mg prefilled liquid Yisaipu for a total of 48 injections or onceweekly 50-mg prefilled liquid Yisaipu for a total of 24 injections are noninferior to twice-weekly 25-mg lyophilized Yisaipu for a total of 48 injections. Similar improvements were also observed with the secondary efficacy outcome ASAS40. Furthermore, approximately $86 \%$ of our patients achieved ASAS clinically important improvement and slightly more than half of the patients achieved ASAS clinically major improvement at week 24, suggesting that improvement in ASAS20 or ASAS40 is associated with clinical improvement in ankylosing spondylitis patients. Our ASAS20 attainment rate at week $24(86 \%)$ is higher than that (57\%) reported in a study of Caucasian ankylosing spondylitis patients who were treated with twice-weekly 25-mg prefilled liquid etanercept [20]. Chou et al. showed that Chinese ankylosing spondylitis patients showed a better shortterm response to etanercept compared to Caucasian ankylosing spondylitis patients [11].

The current study met all the secondary efficacy measures, showing that twice-weekly 25-mg prefilled liquid Yisaipu and once-weekly 50-mg prefilled liquid Yisaipu are noninferior to twice-weekly 25-mg lyophilized Yisaipu. We observed a rapid, robust, and sustained improvement in the patients' and physicians' global assessments of disease activity with approximately $70 \%$ improvement at week 24 in over the baseline in patients receiving twiceweekly 25-mg prefilled liquid Yisaipu, onceweekly 50-mg prefilled liquid Yisaipu, or twiceweekly 25-mg lyophilized Yisaipu, demonstrating that both prefilled liquid Yisaipu and lyophilized etanercept Yisaipu are beneficial in improving the overall health of active ankylosing spondylitis patients, which is consistent with previous findings [9]. Treatment with either prefilled liquid Yisaipu or lyophilized Yisaipu also significantly improved night back pain and total back pain in ankylosing spondylitis patients. Consistently, all the patients exhibited improvement in the number of swollen or tender joints. Significant improvement was also observed in BASMI, MASES, and inflammation (ESR and CRP), indicating that prefilled liquid Yisaipu and lyophilized Yisaipu could lessen disease activity, improve somatic function and spinal mobility of ankylosing spondylitis patients. Our earlier multi-center randomized clinical trial showed an ASAS20 attainment rate of $78 \%$ at week 12 , which is comparable to the current 12 -week rate of $78.89 \%$ for twice-weekly $25-\mathrm{mg}$ prefilled liquid etanercept, $77.14 \%$ for once-weekly $50-\mathrm{mg}$ prefilled liquid etanercept and $72.66 \%$ for twiceweekly 25-mg lyophilized etanercept [21]. Similar improvements were also noted in BASDAI, BASFI, and BASMI in the two studies.

The study also showed that both prefilled liquid Yisaipu and lyophilized Yisaipu were safe and well tolerated by Chinese ankylosing spondylitis patients. No death or malignancy was reported. Common AEs included upper respiratory infections, elevations in hepatic enzymes, injection site reaction, and decreased leucocyte counts, which is similar to earlier studies [22]; these AEs were mild or moderate and disappeared without treatment or after symptomatic treatment. Furthermore, there was no difference in the incidence of AEs between patients treated with prefilled liquid Yisaipu and those with lyophilized Yisaipu. Apart from the benign safety profile, it has been shown that prefilled syringes could also lead to significant annual cost savings in treatment of chronic diseases.

The study also has some limitations. First, the study enrolled Chinese patients and no other ethnicities were included; therefore, the findings may not be completely applicable to other ethnicities. In addition, the study was carried out in tertiary care centers across China and the findings may not be applicable to primary care settings.

\section{CONCLUSIONS}

In conclusion, this randomized, double-blind, phase III parallel-group non-inferiority study demonstrates that once-weekly $50-\mathrm{mg}$ or twice- 
weekly 25-mg prefilled liquid etanerceptbiosimilar Yisaipu is safe and leads to rapid, significant, and sustained improvement in Chinese active ankylosing spondylitis patients and is noninferior to twice-weekly $25-\mathrm{mg}$ lyophilized Yisaipu.

\section{ACKNOWLEDGEMENTS}

We thank the participants of the study.

Funding. The work was supported by Sunshine Guojian Pharmaceutical Co. The study sponsor also funded the journal's Rapid Service Fee.

Medical Writing and/or Editorial Assistance. We thank Dr. Bo Cui at the Ivy Medical Consulting \& Editing for editing this manuscript (funded by Sunshine Guojian Pharmaceutical Co., Shanghai, China).

Authorship. All named authors meet the International Committee of Medical Journal Editors (ICMJE) criteria for authorship for this article, take responsibility for the integrity of the work as a whole, and have given their approval for this version to be published.

Disclosures. This trial was sponsored and designed by Sunshine Guojian Pharmaceutical Co. Gang Tong and Dong Wang are employees at Sunshine Guojian Pharmaceutical Co. The following authors (Dongbao Zhao, Dongyi He, Liqi Bi, Huaxiang Wu, Yi Liu, Zhenbiao $\mathrm{Wu}$, Yang Li, Guochun Wang, Xingfu Li, Chunde Bao, Lindi Jiang, Zhiyi Zhang, Weiguo Xiao, and Feng Huang) declare no personal, financial, commercial, or academic conflicts of interest with the publication of the paper.

Compliance with Ethics Guidelines. The study protocol adhered to the SPIRIT statement and was approved by the ethics committee of all participating institutions (Appendix I). All study subjects provided written informed consent prior to enrollment. The trial was conducted in accordance with the Declaration of
Helsinki and the reporting of the study adhered to the CONSORT statement.

Data Availability. The datasets generated during and/or analyzed during the current study are available from the corresponding author on reasonable request.

Open Access. This article is licensed under a Creative Commons Attribution-NonCommercial 4.0 International License, which permits any non-commercial use, sharing, adaptation, distribution and reproduction in any medium or format, as long as you give appropriate credit to the original author(s) and the source, provide a link to the Creative Commons licence, and indicate if changes were made. The images or other third party material in this article are included in the article's Creative Commons licence, unless indicated otherwise in a credit line to the material. If material is not included in the article's Creative Commons licence and your intended use is not permitted by statutory regulation or exceeds the permitted use, you will need to obtain permission directly from the copyright holder. To view a copy of this licence, visit http://creativecommons.org/licenses/by$\mathrm{nc} / 4.0 /$.

\section{REFERENCES}

1. Braun J, Sieper J. Ankylosing spondylitis. Lancet. 2007;369:1379-90.

2. Braun J, Bollow M, Remlinger G, et al. Prevalence of spondylarthropathies in HLA-B27 positive and negative blood donors. Arthritis Rheum. 1998;41: $58-67$.

3. Zhao J, Huang C, Huang $\mathrm{H}$, et al. Prevalence of ankylosing spondylitis in a Chinese population: a systematic review and meta-analysis. Rheumatol Int. 2020;40:859-72.

4. Sieper J, Braun J, Rudwaleit M, Boonen A, Zink A. Ankylosing spondylitis: an overview. Ann Rheum Dis. 2006;1(3):8-18.

5. Grom AA, Murray KJ, Luyrink L, et al. Patterns of expression of tumor necrosis factor alpha, tumor necrosis factor beta, and their receptors in synovia of patients with juvenile rheumatoid arthritis and 
juvenile spondyloarthropathy. Arthritis Rheum. 1996;39:1703-10.

6. Braun J, Bollow M, Neure L, et al. Use of immunohistologic and in situ hybridization techniques in the examination of sacroiliac joint biopsy specimens from patients with ankylosing spondylitis. Arthritis Rheum. 1995;38:499-505.

7. Ward MM, Deodhar A, Akl EA, et al. American college of rheumatology/spondylitis association of America/spondyloarthritis research and treatment network 2015 recommendations for the treatment of ankylosing spondylitis and nonradiographic axial spondyloarthritis. Arthritis Rheumatol. 2016;68:282-98.

8. van der Heijde D, Song IH, Pangan AL, et al. Efficacy and safety of upadacitinib in patients with active ankylosing spondylitis (SELECT-AXIS 1): a multicentre, randomised, double-blind, placebo-controlled, phase 2/3 trial. Lancet. 2019;394:2108-17.

9. Gorman JD, Sack KE, Davis JC Jr. Treatment of ankylosing spondylitis by inhibition of tumor necrosis factor alpha. N Engl J Med. 2002;346: 1349-56.

10. Brandt J, Khariouzov A, Listing J, et al. Six-month results of a double-blind, placebo-controlled trial of etanercept treatment in patients with active ankylosing spondylitis. Arthritis Rheum. 2003;48: $1667-75$.

11. Chou CT, Tsai CY, Liang TH, et al. Better short-term clinical response to etanercept in Chinese than Caucasian patients with active ankylosing spondylitis. Mod Rheumatol. 2010;20:580-7.

12. Moll JM, Wright V. New York clinical criteria for ankylosing spondylitis: a statistical evaluation. Ann Rheum Dis. 1973;32:354-63.

13. Garrett S, Jenkinson T, Kennedy LG, Whitelock H, Gaisford P, Calin A. A new approach to defining disease status in ankylosing spondylitis: the bath ankylosing spondylitis disease activity index. J Rheumatol. 1994;21:2286-91.
14. Chan AW, Tetzlaff JM, Altman DG, et al. SPIRIT 2013 statement: defining standard protocol items for clinical trials. Ann Intern Med. 2013;158:200-7.

15. Schulz KF, Altman DG, Moher D, CONSORT Group. CONSORT. statement: updated guidelines for reporting parallel group randomised trials. BMJ. 2010;2010(340):c332.

16. Anderson JJ, Baron G, van der Heijde D, Felson DT, Dougados M. Ankylosing spondylitis assessment group preliminary definition of short-term improvement in ankylosing spondylitis. Arthritis Rheum. 2001;44:1876-86.

17. Heuft-Dorenbosch L, Spoorenberg A, van Tubergen A, et al. Assessment of enthesitis in ankylosing spondylitis. Ann Rheum Dis. 2003;62:127-32.

18. https://ctep.cancer.gov/protocolDevelopment/ electronic_applications/ctc.htm.

19. Group ICoHEW. International conference on harmonisation of technical requirements for registration of pharmaceuticals for human use. ICH harmonised tripartite guideline. Guideline for good clinical practice.1997 CFR \& ICH Guidelines.1997.

20. Davis JC Jr, van der Heijde D, Braun J, et al. Recombinant human tumor necrosis factor receptor (etanercept) for treating ankylosing spondylitis a randomized, controlled trial. Arthritis Rheum. 2003;48:3230-6.

21. Huang F, Deng X, Zhang Y, et al. A multicenter, double blind randomized controlled trial of recombinant type II tumor necrosis factor receptor antibody fusion protein for ankylosing spondylitis. Chin J Rhematol. 2008;7:314-20.

22. Du F, Bao C, Zhang F. China etanercept safety monitoring and study coordination group. study on the safety of recombinant type II tumor necrosis factor receptor antibody fusion protein in combination with disease-modifying anti-rheumatic drug for rheumatoid arthritis in Chinese population. Chin J Rhematol. 2011;15:850-4. 